\title{
Electrical Characterization of Li-Ion Battery Modules for Second-Life Applications
}

\author{
Daniel Kehl $^{1, *}$, Torben Jennert ${ }^{1}$, Frank Lienesch ${ }^{2} \mathbb{D}$ and Michael Kurrat ${ }^{1}$ \\ 1 Elenia Institute for High Voltage Technology and Power Systems, Technische Universität Braunschweig, \\ Schleinitzstraße 23, 38106 Braunschweig, Germany; t.jennert@tu-braunschweig.de (T.J.); \\ m.kurrat@tu-braunschweig.de (M.K.) \\ 2 Physikalisch-Technische Bundesanstalt (PTB), Bundesallee 100, 38116 Braunschweig, Germany; \\ Frank.Lienesch@ptb.de \\ * Correspondence: d.kehl@tu-braunschweig.de; Tel.: +49-531-391-9732
}

Citation: Kehl, D.; Jennert, T.; Lienesch, F.; Kurrat, M. Electrical Characterization of Li-Ion Battery Modules for Second-Life Applications. Batteries 2021, 7, 32. https://doi.org/10.3390/ batteries7020032

Academic Editor: Mohammad (Mim) Rahimi

Received: 22 February 2021

Accepted: 26 April 2021

Published: 13 May 2021

Publisher's Note: MDPI stays neutral with regard to jurisdictional claims in published maps and institutional affiliations.

Copyright: (c) 2021 by the authors. Licensee MDPI, Basel, Switzerland. This article is an open access article distributed under the terms and conditions of the Creative Commons Attribution (CC BY) license (https:// creativecommons.org/licenses/by/ $4.0 /)$.

\begin{abstract}
The reuse and repurposing of lithium-ion batteries for transportation in stationary energy systems improve the economic value of batteries. A precise suitability test at the beginning of the second life is therefore necessary. Common methods such as electrochemical impedance spectroscopy (EIS) and current interrupt (CI) analysis, as well as capacity analysis, can be used for testing. In this paper, these methods are studied from the aspects of test duration, sensitivity and acquisition costs of the measuring instruments. For this purpose, tests are carried out on battery modules, which were used for transportation. It is shown that subtle differences are better detected with EIS and less accurately with the CI method. The test duration is fastest with the CI method, followed by EIS and the capacity test. Strongly aged modules are reliably detected with all methods.
\end{abstract}

Keywords: modules; characterization; aging; current interrupt; electrochemical impedance spectroscopy; second use; second life; lithium-ion battery

\section{Introduction}

The new circular economy action plan from the European Commission aims to facilitate the reuse and repurposing of batteries [1]. Due to the high energy density, efficiency close to $95 \%$ and a low self-discharge when not in use, lithium-ion batteries are mainly used in many applications [2].

Kwade et al. investigated the current status and challenges for automotive battery production technologies. One aspect is the life cycle consideration from manufacturing to recycling [3]. To maximize the value of batteries for transportation, second use in stationary energy systems (SESSs) is essential. Second use in a SESS is called second life. Automotive manufacturers recommend replacing batteries when the remaining energy capacity reaches $70 \%$ to $80 \%$ of the original energy capacity [4]. Rallo et al. [5] found that the aging of batteries plays a significant role in economic results, besides the price of batteries. It is expected that the price of batteries will decrease due to the volume effect of growing electromobility. This development will make SESSs economically interesting [5]. Knowing the aging and speed of aging is relevant for the safe operation of battery modules of a second-life battery storage system, as the risk of damage increases with progressive aging [6,7].

To determine the aging of used battery modules, characterization of the state of health $(\mathrm{SOH})$ is necessary. Access to battery management system (BMS) data from electric vehicles would be helpful for $\mathrm{SOH}$ prediction, but this access is usually protected by the manufacturer [8]. The most used indicator for the $\mathrm{SOH}$ is the ratio of the nominal capacity to the initial capacity. This method is time consuming and thus expensive, as capacity determination usually requires at least a complete charge and discharge cycle [9,10]. Two faster techniques are electrochemical impedance spectroscopy (EIS), where the impedance 
of the battery is measured at different frequencies, and the current interrupt (CI) method, where a voltage drop (or rise) is analyzed by applying a load (or charge) pulse [10-12].

Waag et al. [12] investigated the dependency of battery impedance on various conditions (SOC, temperature, short-time previous history, current rate) and aging states. Their results show the influence of the internal and external conditions on the measurement methods. The sensitivity of the characterization methods was not compared, and the applicability of the tests for incoming goods inspection was beyond the scope of their study.

Wildfeuer et al. [13] used the CI and EIS methods to characterize battery cells in different interconnections. At the module level, they observed an increase in the internal resistance over the full SOC range after the cyclization of the module. Because different interconnections were analyzed, only one module was examined. EIS measurements at the module level were not performed.

Eddahech et al. [14] studied the influence of the $\mathrm{SOH}$ on the constant voltage (CV) phase during the charging process. They discovered a relationship between capacity loss and reduced charging time in the $\mathrm{CV}$ phase. However, a charging process is necessary to perform this characterization. Because the $\mathrm{CV}$ phase takes about $30 \%$ of the charging time due to overvoltages, fast characterization for an incoming goods inspection is not feasible. Furthermore, the $\mathrm{CV}$ voltage must be reached to perform this characterization. Weng et al. [15] studied the incremental capacity analysis (ICA) method to monitor the $\mathrm{SOH}$ of battery modules and packs. The voltage plateaus on the charging/discharging curve, which are displayed as peaks in the incremental capacity curve, are dependent on the $\mathrm{SOH}$ and are related to the intercalation process. For this characterization procedure, complete charge/discharge curves at low currents $(<1 / 25 \mathrm{C})$ must be available. Therefore, this characterization method is not feasible for incoming goods inspection.

The influence of contact resistances at the cell pack (CP) level of modules is discussed by Campestrini et al. [16]. Campestrini et al. observed increased contact resistance on the $\mathrm{CP}$ level of the modules they built from cells. Cell resistance at the $\mathrm{CP}$ level seemed higher than it actually was. Therefore, this study focused on evaluating the module level and not each cell pack level of the modules. Disassembling modules into cell packs and reassembling equally aged cell packs also involves additional work; therefore, a general quality distinction of the modules should be sufficient for an inwards goods test.

To summarize, there are currently no studies showing the dependency of CI, EIS and capacity tests at the module level at the beginning of second life, and there is no comparison of their sensitivity to detect the $\mathrm{SOH}$. The primary aim of this study is to investigate the dependencies of the named methods and to classify the applicability under the aspects of test duration, sensitivity and investment costs of the measuring devices. For this reason, five battery modules from an electric vehicle (EV) are analyzed with the CI and EIS methods. To apply the methods, the requirements of the measurement setup are considered in more detail. Subsequently, the results are compared to the measured capacity of the modules, and the sensitivity of each method is evaluated.

This makes it possible to select the most suitable measurement method for the desired application in practice. The CI method, which is an easy-to-integrate measurement method, can be applied without interruption during operation and is therefore considered more closely.

\section{Material and Methods}

The characterization procedure is divided into two parts. First, the CI method was applied using a test procedure, then the modules were tempered for $16 \mathrm{~h}$ and the EIS method was applied.

For both measurement techniques, it is crucial to use the four-wire measurement to reduce the voltage error caused by the current in the measurement wires. 


\subsection{Test Objects}

The $\mathrm{SOH}$ investigation with the methods mentioned in the introduction was carried out on five automotive battery modules. The cell chemistry is NMC. The cells of the modules are interconnected in 4s3p (see Figure 1).

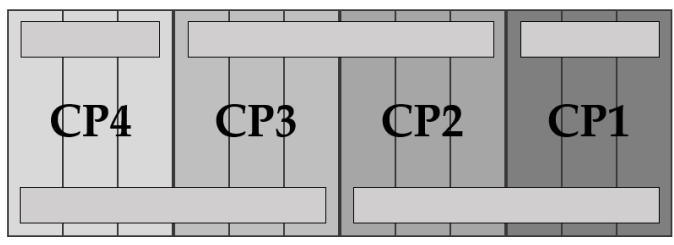

Figure 1. Schematic representation of the cell interconnection in the battery module showing the parallel connection results of 3 cells in a cell pack (CP).

The nominal capacity is given with $111 \mathrm{Ah}$. Voltage limits were given from 12.8 to $16.8 \mathrm{~V}$ [17]. No other aging and previous usage information were given.

\subsection{Method and Capacity Determination}

Cell voltages were measured with a National Instruments PXI System. The Chassis 1085 with a PXIe-4300 ADC measurement module was used to capture the cell pack voltages. As measurement wires, twisted-pair cables with shielded aluminum foil around the pairs and another shielding around the whole cable were used. The shielding was attached to the module housing to ensure potential equalization. To evaluate the module voltage, the cell pack voltages were summed up. The current was measured with a LEM HTA 100-S Hall effect sensor. The modules were placed in a temperature cabinet, which keeps the temperature at $20^{\circ} \mathrm{C}$ to ensure that the battery modules are tested under equal conditions. A Greenlight module tester was used for the power supply.

Because the modules are supplied with 1C, very large currents (111 A) flow for the given capacity of the battery modules. The large currents next to the test leads for the voltages lead to a demanding measurement setup to reliably detect the very small internal resistance. In Figure 2, the experimental setup is shown.

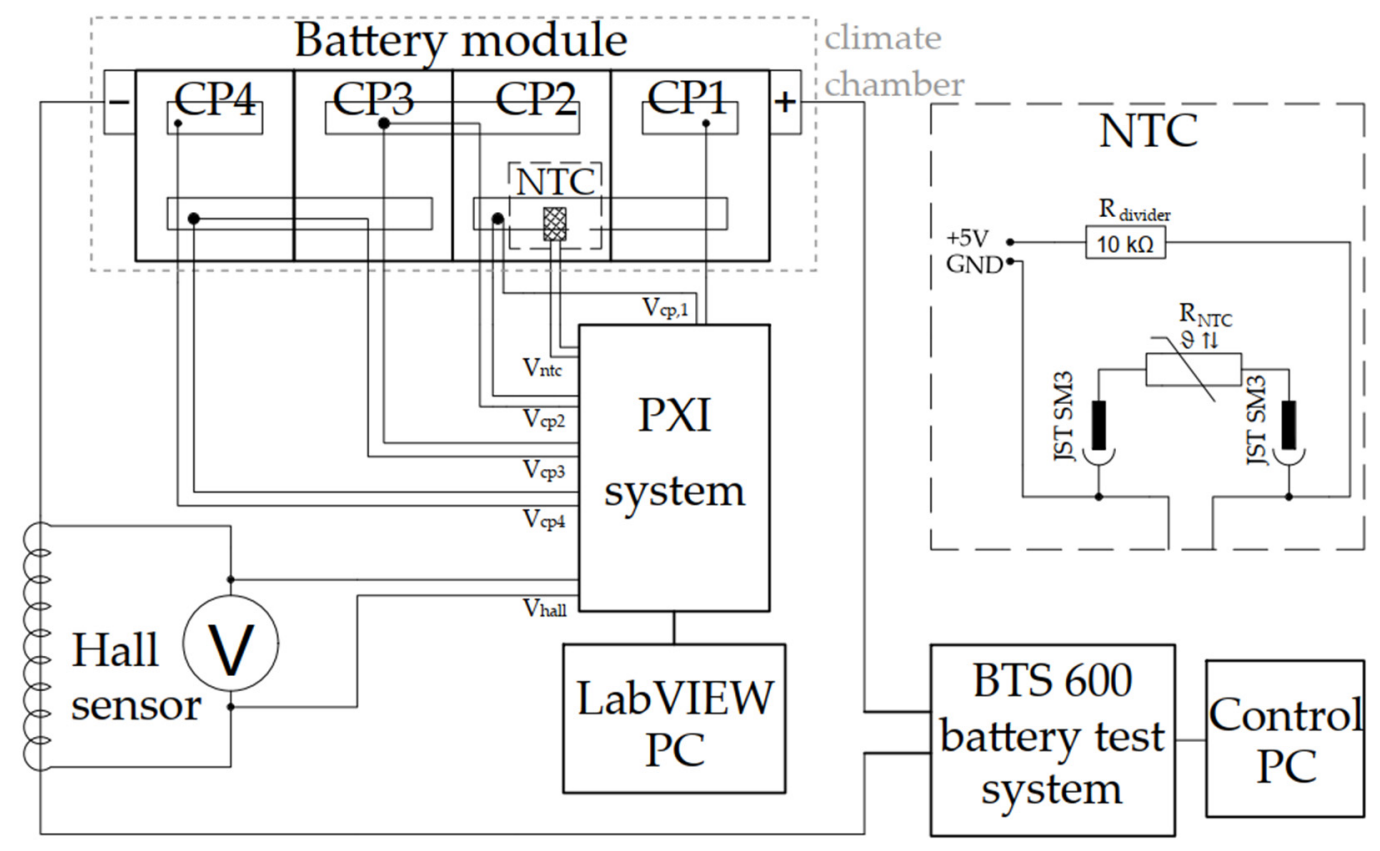

Figure 2. Schematic representation of the experimental setup for the testing procedure. 
To evaluate the state of health of the modules, a testing procedure, illustrated in Figure 3, was applied to each module. The testing procedure principle is shown in Table 1.

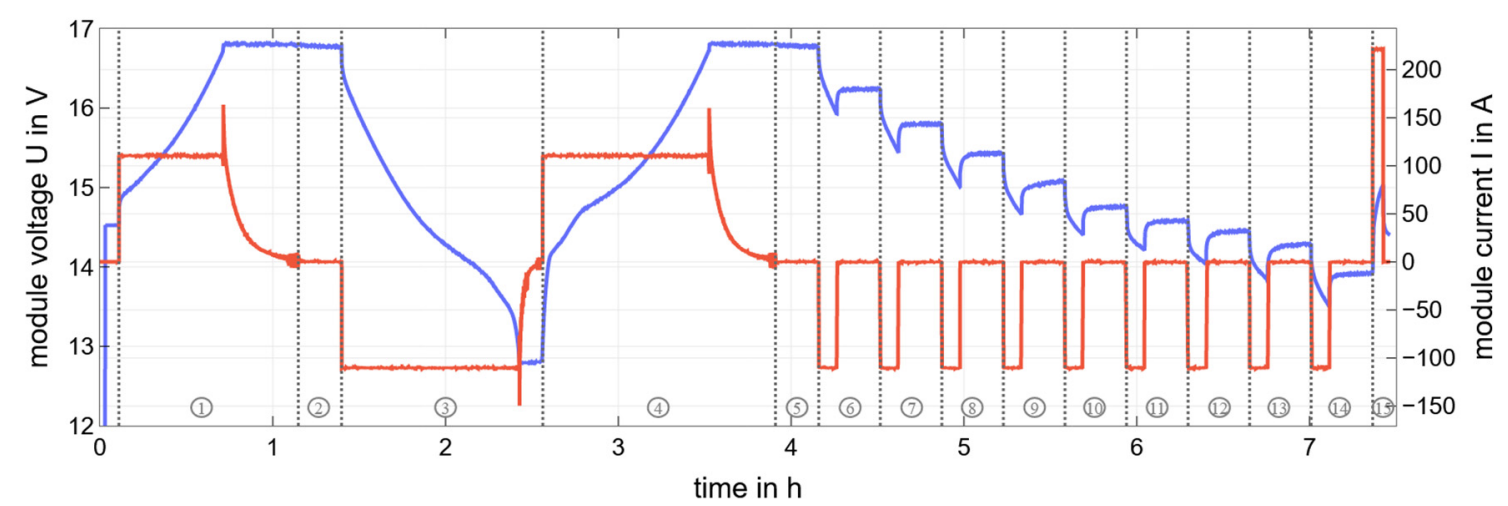

Figure 3. The testing procedure consists of different steps that can be seen over time: voltage curve of the battery module in the test (blue); current curve (red) of the battery module in the test.

Table 1. Testing procedure steps to evaluate the capacity and inner resistance of the battery modules at different SOCs.

\begin{tabular}{ccc}
\hline Step & Description & Parameters and Conditions \\
\hline 1 & Full charge & $@ 1 C, C C+C V$ \\
2 & Pause & 15 min \\
3 & Capacity determination & Discharge $@ 1 C, C C+C V$ \\
4 & Full charge & $@ 1 C, C C+C V$ \\
5 & Pause & 15 min \\
$6-14$ & Recurring discharge to $10 \%$ SoC & $@ 10 \%$ SOC steps +15 min relaxation \\
15 & Charge & Charge while battery voltage $<14.9 \mathrm{~V} @ 2 \mathrm{C}$ \\
\hline
\end{tabular}

Due to the undefined state of charge at delivery, the modules were first fully charged to $16.8 \mathrm{~V}$. For acclimatization, a pause of $15 \mathrm{~min}$ was integrated. Afterward, the capacity of the battery modules was tested with a CC/CV discharge with a current of $1 \mathrm{C}$.

The next step consists of a charging process for further module evaluation. By discharging the modules in $10 \%$ SOC steps and a subsequent relaxation time of $15 \mathrm{~min}$, the CI method was implemented.

To store the modules, they were charged with a current of $2 \mathrm{C}$ to $14.9 \mathrm{~V}$. Due to overvoltage during charging, a voltage corresponding to a SOC of $30 \%$ was reached after $16 \mathrm{~h}$ when the EIS measurement for each module was performed. By choosing a SOC of $30 \%$, peak heat can be reduced by $50 \%$ compared to a SOC of $50 \%$ in the event of a thermal runaway $[17,18]$. This is a recommended SOC from a safety point of view [19]. Because safe transport of second-life battery modules with a SOC of up to $30 \%$ is possible, this SOC was selected for the incoming goods test with the EIS measurements.

The capacity is calculated by the following equation:

$$
Q=\int i(t) \cdot d t
$$

The internal resistance is calculated as followed:

$$
R_{i}(t)=\left|\frac{\Delta u(t)}{\Delta i(t)}\right|=\left|\frac{U\left(t_{0}-50 m s\right)-u(t)}{I\left(t_{0}-50 m s\right)-i(t)}\right|
$$

In order to calculate and plot the internal resistances, a Python script was used. The Python script integrates the current to determine the capacity of the modules at a $1 \mathrm{C}$ discharge. 
Wildfeuer et al. [13] studied internal resistance curves for the timepoints 0.1, 2 and $10 \mathrm{~s}$ at the module level. Because only a single module was considered, changes in the internal resistance curve could be studied at different SOCs. The authors define the most meaningful timepoint by considering the difference of the internal resistance value of the worst module to the internal resistance value of the module with the next lower value for the timepoints $0,0.1,0.2,0.5,1$ and $60 \mathrm{~s}$ during the relaxation phase. To ensure a comparison between the results of the CI and EIS methods, the evaluation of the internal resistances takes place at the same SOC that was selected for the EIS measurements.

\subsection{EIS Method}

A Reference 3000 AE (Gamry Inc., Warminster, PA, USA) is used in combination with a Gamry Reference 30k Booster to perform the EIS measurements. The modules were tested in a frequency range from $5 \mathrm{kHz}$ to $20 \mathrm{MHz}$ with 10 measurement points per decade. The measuring device of the company Gamry Inc. automatically readjusted the excitation amplitude. The used function is called "Hybrid-EIS." Here, the maximum voltage change was set to $20 \mathrm{mV}$ to ensure a pseudo-linear operating point of the four serial cell packs. The excitation currents vary in this range depending on the excitation frequency between 8 and $25 \mathrm{~A}$. The EIS measurements were performed the next day after the CI measurements (approximately $16 \mathrm{~h}$ ).

The experimental setup is shown in Figure 4.

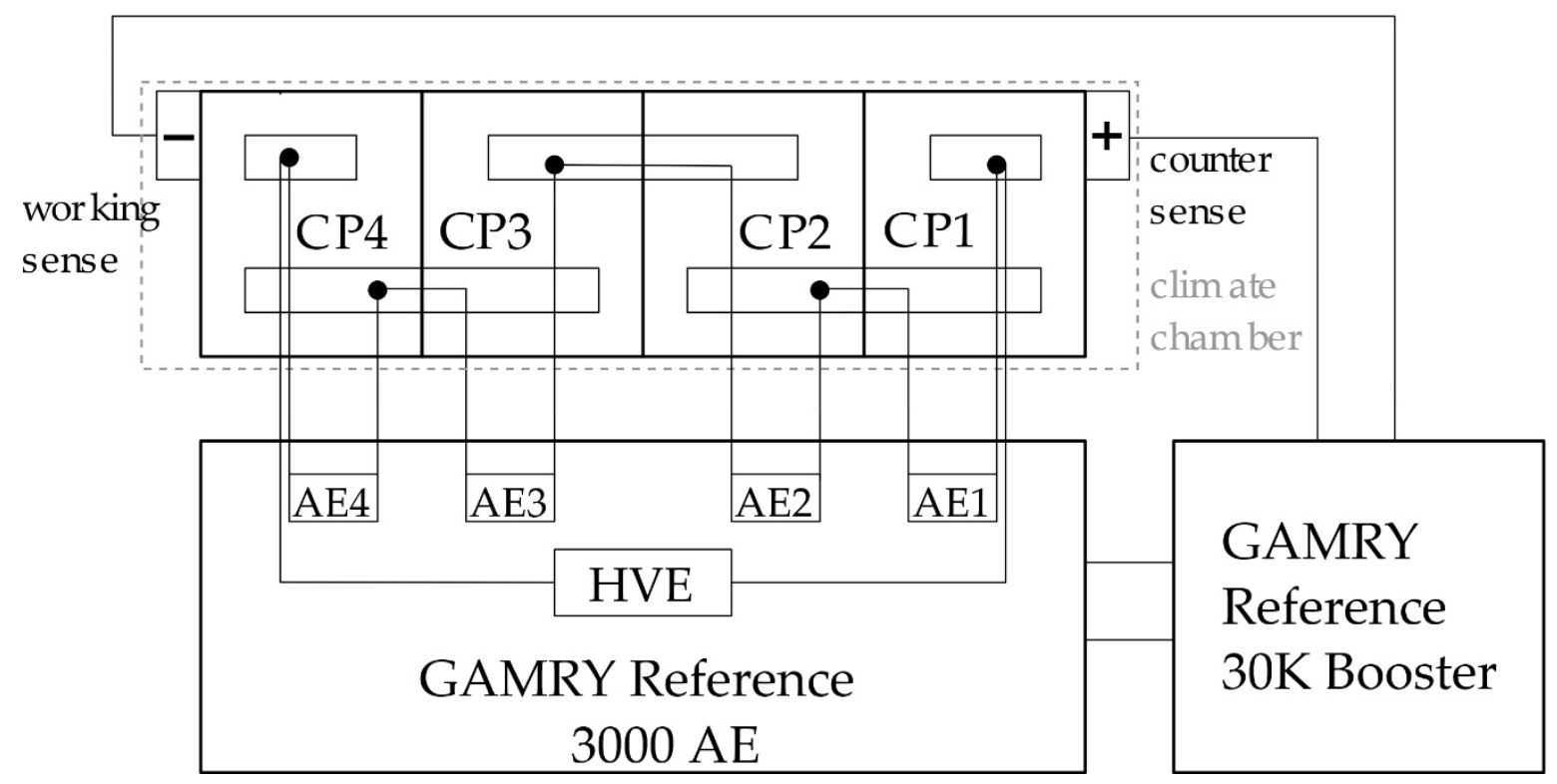

Figure 4. Experimental setup for the EIS measurements in the climate chamber.

To generate the impedance spectra, the battery modules or single-battery cells were stimulated by an alternating current with varying frequency, and the voltage response was measured. Here, it is important to pay attention to the causes of measurement errors such as parasitic inductive coupling, electromagnetic interferences, systematic errors caused by contact resistance change, violation of the system requirements (linearity, time invariance, causality) [6,20-22], different location of measurement lines and the use of uncalibrated additional adapters. A booster is needed to generate enough alternating current for EIS with battery modules or very large single cells. The effect on the impedance spectrum when the current excitation is too low is shown in Figure 5. 


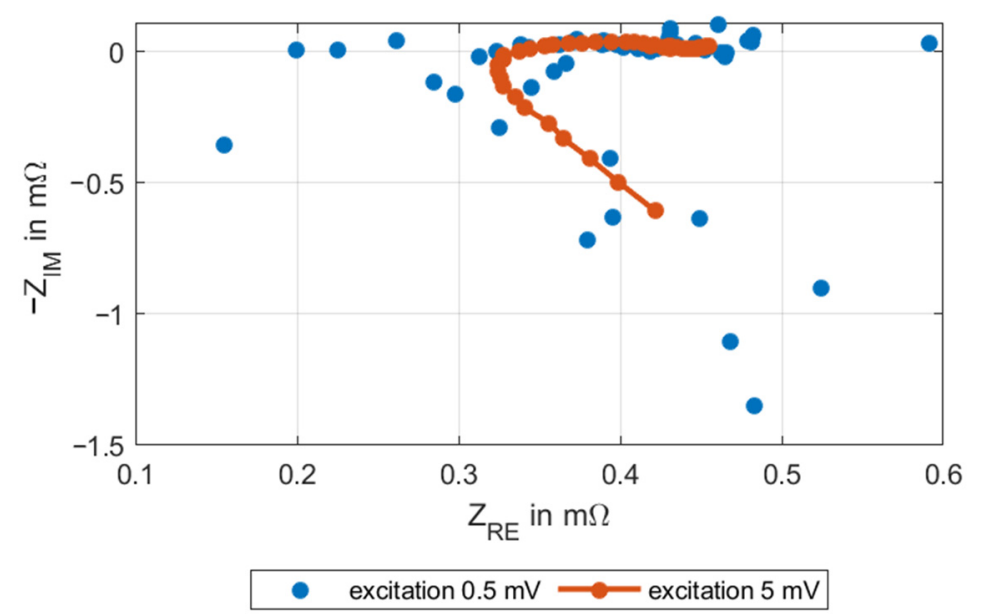

Figure 5. Excitation dependency for EIS measurements tested with a single test cell (64 Ah).

Before evaluating the module results, the influence of temperature, SOC and current excitation was investigated. For these tests, test cells that did not correspond to the cells in the modules were used.

If the current excitation is too small, the voltage change will be too small for meaningful measurements. A comparison with an excitation that is too low is shown in Figure 5.

As soon as an almost error-free EIS measurement is possible, it depends on the following three main factors: temperature, $\mathrm{SOC}, \mathrm{SOH}$. These dependencies were also studied by Waag et al. [12] and Zhu et al. [23] at the cell level.

The dependencies of temperature and SOC are shown in Figure 6.

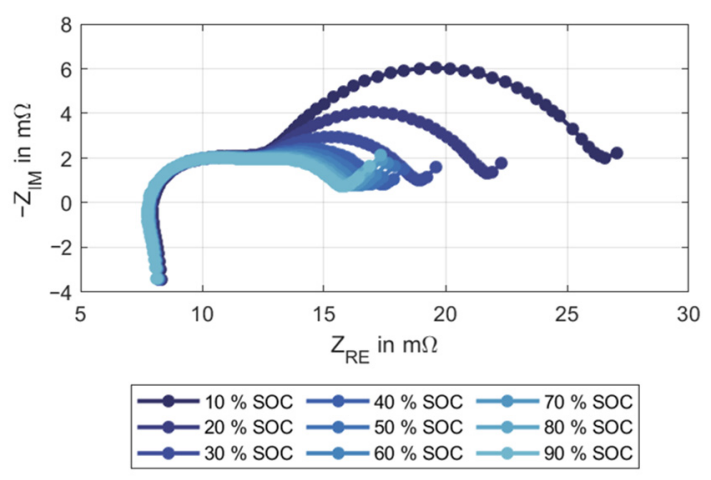

(a)

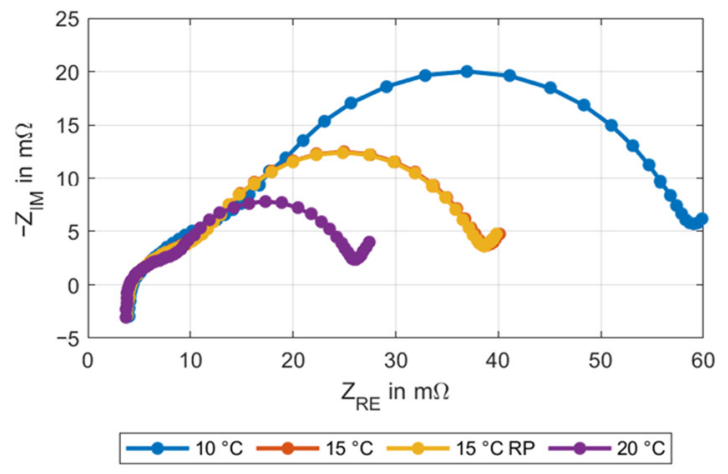

(b)

Figure 6. Schematic representation of spectra: (a) SOC dependence of the single test cell (5 Ah) measurement at $20{ }^{\circ} \mathrm{C}(\mathbf{b})$; temperature dependence of the single test cell (5 Ah) measurement at $20 \%$ SOC.

The temperature is assumed to be constant by using a climate chamber and $16 \mathrm{~h}$ of tempering time. The SOC must be determined precisely; for this purpose, $\mathrm{OCV}$ is consulted additionally.

Reversible aging effects, which are described by Petzl et al. [24], are brought to the same level for all modules by the previous $\mathrm{CI}$ test procedure. Thus, the temperature and $\mathrm{SOC}$ of the measurements are kept constant so that the $\mathrm{SOH}$ is the only parameter that affects the measurement results.

For the evaluation of the impedance spectra, the characteristic points from Figure 7 were defined. 


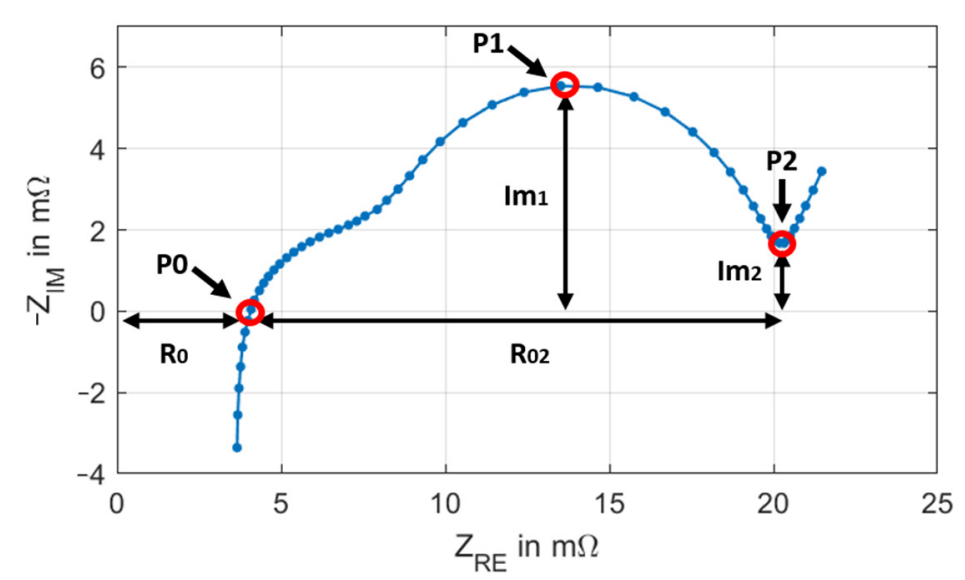

Figure 7. Schematic representation of an impedance spectrum with characteristic points that were used for evaluation.

$R_{02}$ (see Formula (3)), $I_{1}$ (see Formula (4)) and $\operatorname{Im}_{2}$ (see Formula (5)) were defined as indicators, which were used for module evaluation.

$$
\begin{gathered}
R_{02}=Z_{R E}(P 2)-Z_{R E}(P 0) \\
I m_{1}=Z_{I M}(P 1) \\
I m_{2}=Z_{I M}(P 2)
\end{gathered}
$$

Regarding evaluation, there are different challenges to precise the results, which can

\begin{tabular}{|c|c|c|c|}
\hline Point & $\operatorname{Re}(Z)$ & $\operatorname{Im}(Z)$ & Frequency \\
\hline P0 & Indirect informativeness & $\stackrel{\text { def }}{=} 0$, necessary to define $P 0$ & Depends on the experimental setup \\
\hline$P 1$ & Vulnerable to measurement and evaluation errors & Robust to measurement- and evaluation errors & Robust but has to be interpolated \\
\hline$P 2$ & Good measurability & Good measurability & Unequivocal allocation not possible \\
\hline
\end{tabular}
be seen in Table 2.

Table 2. Evaluability of the characteristic points in comparison.

Point $P 0$ is the intersection from the impedance spectra with the real axis, representing the ohmic resistance [25]. Following this, the imaginary value is 0 and has no further information. The measuring frequency at this point strongly depends on the experimental setup and the location of the measurement wires, which can produce additional inductive coupling. Thus, the resulting information content is given by the real part of $P 0$. Figure $6 a, b$ shows the stability of the real part under different influences of SOC and temperature, which results from a high gradient of the spectra at this point.

Point $P 1$ is the local maximum between $P 0$ and $P 2$. Here, the gradient is 0 ; in addition, in a wide range near to this point, the gradient is small. As a result, small differences in the evaluation of the imaginary part will show a big impact on the real part of the measurement. On the contrary, big differences in the evaluation of the real part will only show small differences for the imaginary part, which ensures the robustness of the measurements. At high SOCs, it can be difficult to determine $P 2$.

Point $P 2$ is the local minimum at low measurement frequencies. This point represents the polarization resistance [13]. In this area, several measurement points of different frequencies are often very close to each other, especially at high SOCs. Due to the measurement uncertainty, it is not possible to define one of these points as the true minimum. Concurrently, the accumulation of measurement points with small spreading will lead to a sufficient result regarding a machine-based evaluation.

Using $P 0, P 1$ and $P 2$, it is possible to derive three scales for comparing the impedance spectra of the modules with each other. First attempts showed that the real part of the 
spectra can be distorted by offsets. These pure ohmic offsets $(0.07 \mathrm{mOhm}$ as usual for this experimental setup) can vary between the measurements of the modules but will be stable for a single module measurement. The authors expect these errors caused by contact resistances, despite all electrical contacts, were cleaned carefully. However, it is easy to erase this measurement error by regarding the differences from $P 0$ and $P 2$ in the spectra, as this measurement error will affect both real parts in the same way. Fortunately, the imaginary parts will not be distorted by these errors. As a result, the following three scales will be used to compare the impedance spectra of the modules with each other.

\section{Results and Discussion}

First, the results of the CI method are evaluated. Afterward, the results of the EIS methods are presented. Finally, the results are compared to the classic capacity test (classic $\mathrm{SOH})$.

\subsection{Method}

The internal resistance curves of the battery modules at 30\% SOC in the relaxation phase are shown in Figure 8. The course of the module resistances directly after changing the current show the greatest differences; therefore, this area is shown enlarged.

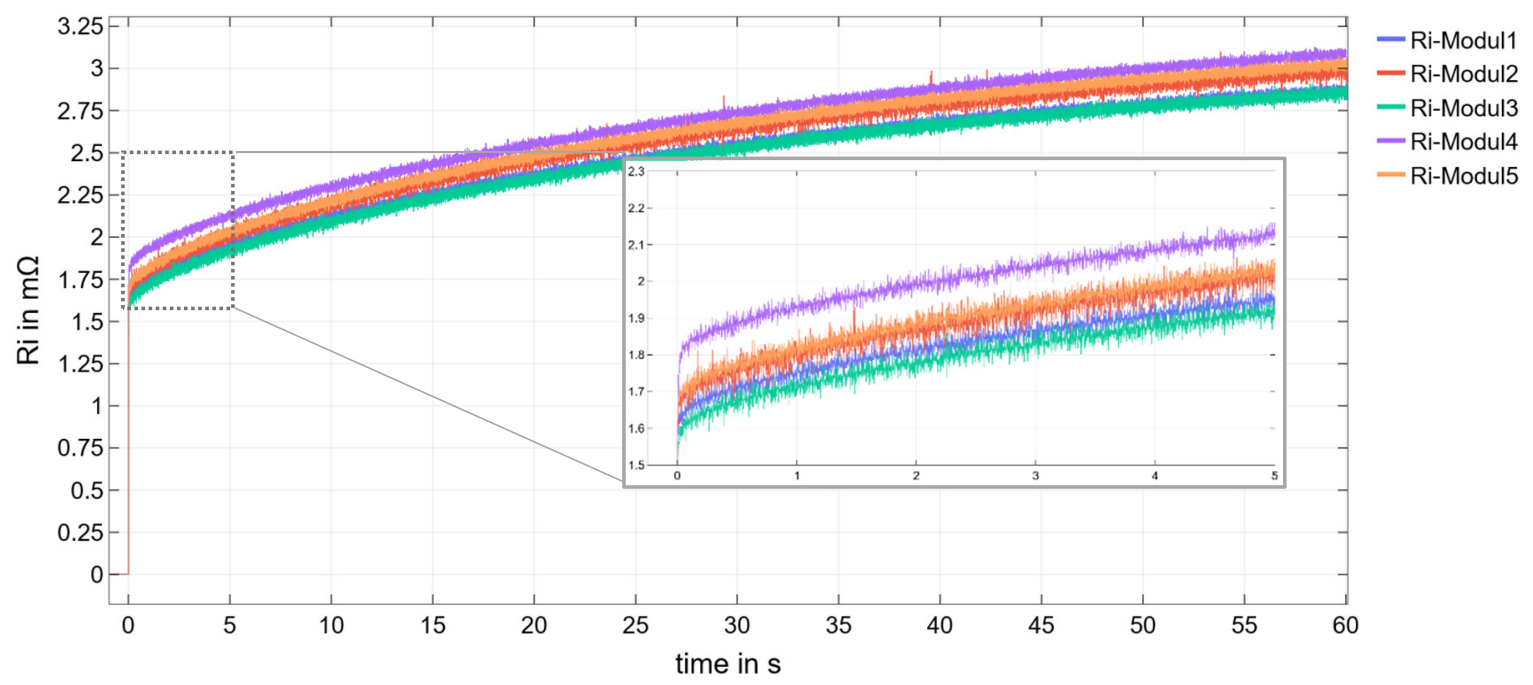

Figure 8. Internal resistance curves of the modules calculated from the voltage change in the relaxation phase at $30 \%$ SOC. In order to better recognize the differences in the first seconds, this is shown enlarged. The raw data display contains measurement noise, which underlines the importance of precise voltage measurement.

It can be seen that Module 4 always has the highest internal resistance values. The difference is greater in the front area than in the rear area. This raises the question of when the difference and thus the evaluation become best visible at what time.

To determine the most meaningful timepoint, the timepoints $0.1,0.2,0.5$ and $1 \mathrm{~s}$ such as $60 \mathrm{~s}$ in the relaxation phase were evaluated (see Table 3). It can be seen that $0.5 \mathrm{~s}$ in the relaxation phase shows the largest difference and is therefore used for evaluation. A stationary current that lasts for $0.5 \mathrm{~s}$ is very likely to be found in the real operation of battery storage [26]. 
Table 3. Comparison of internal resistances at different time points, measured in the relaxation phase at $30 \%$ SOC with the CI method.

\begin{tabular}{|c|c|c|c|c|c|c|}
\hline$t$ in $s$ & $\begin{array}{c}\text { Module } 1 \\
\text { in } m \Omega\end{array}$ & $\begin{array}{c}\text { Module } 2 \\
\text { in } m \Omega\end{array}$ & $\begin{array}{c}\text { Module } 3 \\
\text { in } \mathrm{m} \Omega\end{array}$ & $\begin{array}{c}\text { Module } 4 \\
\text { in } \mathrm{m} \Omega\end{array}$ & $\begin{array}{c}\text { Module } 5 \\
\text { in } \mathrm{m} \Omega\end{array}$ & $\begin{array}{l}\Delta \mathrm{R}_{\mathrm{i}-\mathrm{M} 4-\mathrm{MX}} \\
\quad \text { in } \mathrm{m} \Omega\end{array}$ \\
\hline 0 & 1.41 & 1.38 & 1.41 & 1.46 & 1.42 & 0.04 \\
\hline 0.1 & 1.65 & 1.70 & 1.64 & 1.83 & 1.75 & 0.08 \\
\hline 0.2 & 1.68 & 1.70 & 1.65 & 1.85 & 1.75 & 0.10 \\
\hline 0.5 & 1.70 & 1.75 & 1.65 & 1.89 & 1.78 & 0.11 \\
\hline 1 & 1.76 & 1.80 & 1.71 & 1.93 & 1.83 & 0.10 \\
\hline 60 & 2.84 & 3.00 & 2.88 & 3.08 & 3.03 & 0.05 \\
\hline
\end{tabular}

To examine the best $\mathrm{SOC}$ to evaluate the $\mathrm{SOH}$ of the modules, different working points are considered in Table 4.

Table 4. Comparison of different SOC working points at $0.5 \mathrm{~s}$ in the relaxation phase, internal resistances are normalized to the best module.

\begin{tabular}{|c|c|c|c|c|c|c|}
\hline SOC in $\%$ & Module 1 & Module 2 & Module 3 & Module 4 & Module 5 & $\Delta \mathbf{R}_{\mathrm{i}-\mathrm{M} 4-\mathrm{MX}}$ in $\%$ \\
\hline 90 & $100 \%(1.55 \mathrm{~m} \Omega)$ & $101.03 \%$ & $102.19 \%$ & $111.73 \%$ & $101.55 \%$ & $9.54 \%$ \\
\hline 80 & $100 \%(1.57 \mathrm{~m} \Omega)$ & $100.51 \%$ & $100 \%$ & $112.79 \%$ & $104.20 \%$ & $8.59 \%$ \\
\hline 70 & $102.92 \%$ & $100 \%(1.54 \mathrm{~m} \Omega)$ & $105.91 \%$ & $116.11 \%$ & $104.94 \%$ & $10.20 \%$ \\
\hline 60 & $100 \%(1.61 \mathrm{~m} \Omega)$ & $100.68 \%$ & $100.99 \%$ & $111.48 \%$ & $103.16 \%$ & $8.31 \%$ \\
\hline 50 & $101.17 \%$ & $102.10 \%$ & $100 \%(1.62 \mathrm{~m} \Omega)$ & $110.17 \%$ & $102.28 \%$ & $7.89 \%$ \\
\hline 40 & $100 \%(1.67 \mathrm{~m} \Omega)$ & $102.57 \%$ & $101.38 \%$ & $111.18 \%$ & $102.69 \%$ & $8.49 \%$ \\
\hline 30 & $103.58 \%$ & $106.13 \%$ & $100 \%(1.65 \mathrm{~m} \Omega)$ & $114.68 \%$ & $108.01 \%$ & $6.67 \%$ \\
\hline 20 & $100 \%(1.73 \mathrm{~m} \Omega)$ & $106.35 \%$ & $100.06 \%$ & $110.57 \%$ & $106.70 \%$ & $3.87 \%$ \\
\hline 10 & $102.85 \%$ & $105.70 \%$ & $100 \%(1.82 \mathrm{~m} \Omega)$ & $109.27 \%$ & $105.32 \%$ & $3.57 \%$ \\
\hline
\end{tabular}

For this experimental setup, it is shown that the best working point to evaluate the module $\mathrm{SOH}$ is at $70 \% \mathrm{SOC}$ after $0.5 \mathrm{~s}$ in the relaxation phase.

Figure 9 shows a $3 \mathrm{D}$ view of the measured values. Here, the amount of charge is integrated into the evaluation by the capacity measurement. The charge quantity describes the aging state according to the often-used classical $\mathrm{SOH}$ definition.

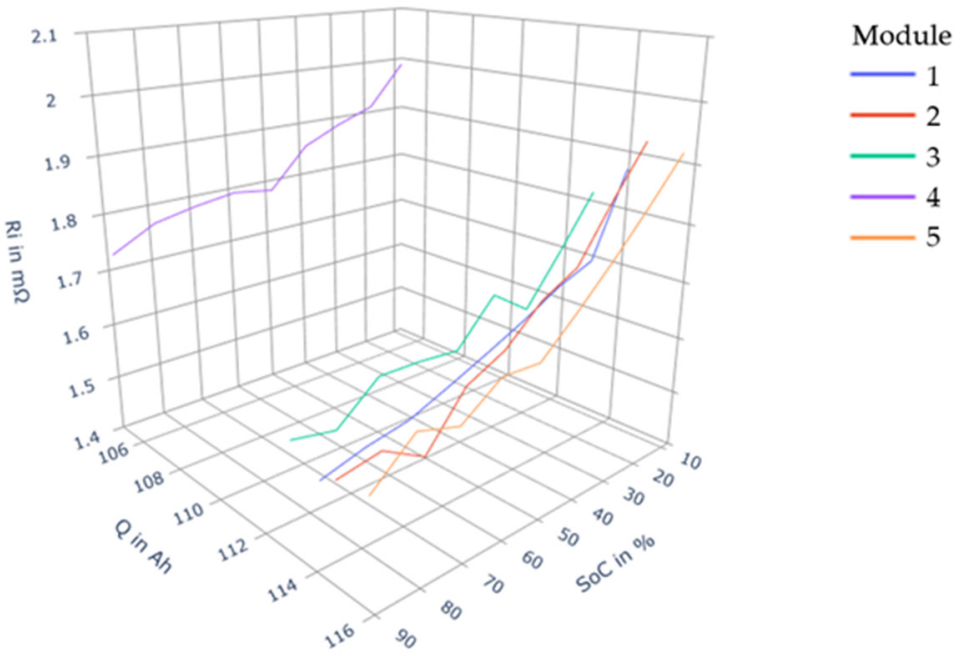

Figure 9. Three-dimensional (3D) characteristics of CI measurements. The increase in the internal resistance to low SOC is noticeable, and Module 4 (printed in purple color) has a significantly larger internal resistance curve. The charge quantity is plotted negatively because it is counted negatively in the discharge direction. 
It can be seen that Module 4 always shows higher values than the other modules. This correlates with the consideration of the capacity test. The results of the internal resistances are, however, more differentiable in the further evaluation than the capacity test and can be determined during the operation of the system.

Because the comparability to the EIS measurement must be given, in the following, the evaluation of the EIS measurements is performed at 30\% SOC (see Figure 10).

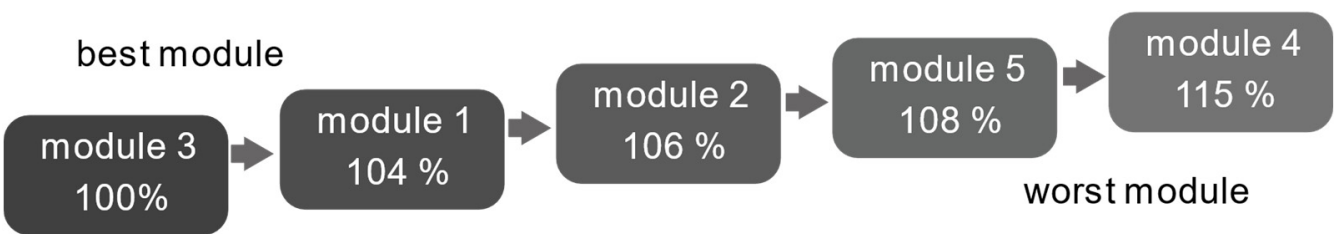

Figure 10. Quantitative evaluation of module aging by the CI method at 30\% SOC.

\subsection{EIS Method}

Figure 11 shows that the impedance spectra vary between the measured modules. The larger the half arcs spread out, the older the battery. The measurand is big enough that module differences are visible regardless of measurement uncertainties. For easier visibility, the spectra from Modules 1 and 3 were shifted toward P0 from the other modules. This shifting has no effect on the spectra's evaluation because of the difference-based evaluation.

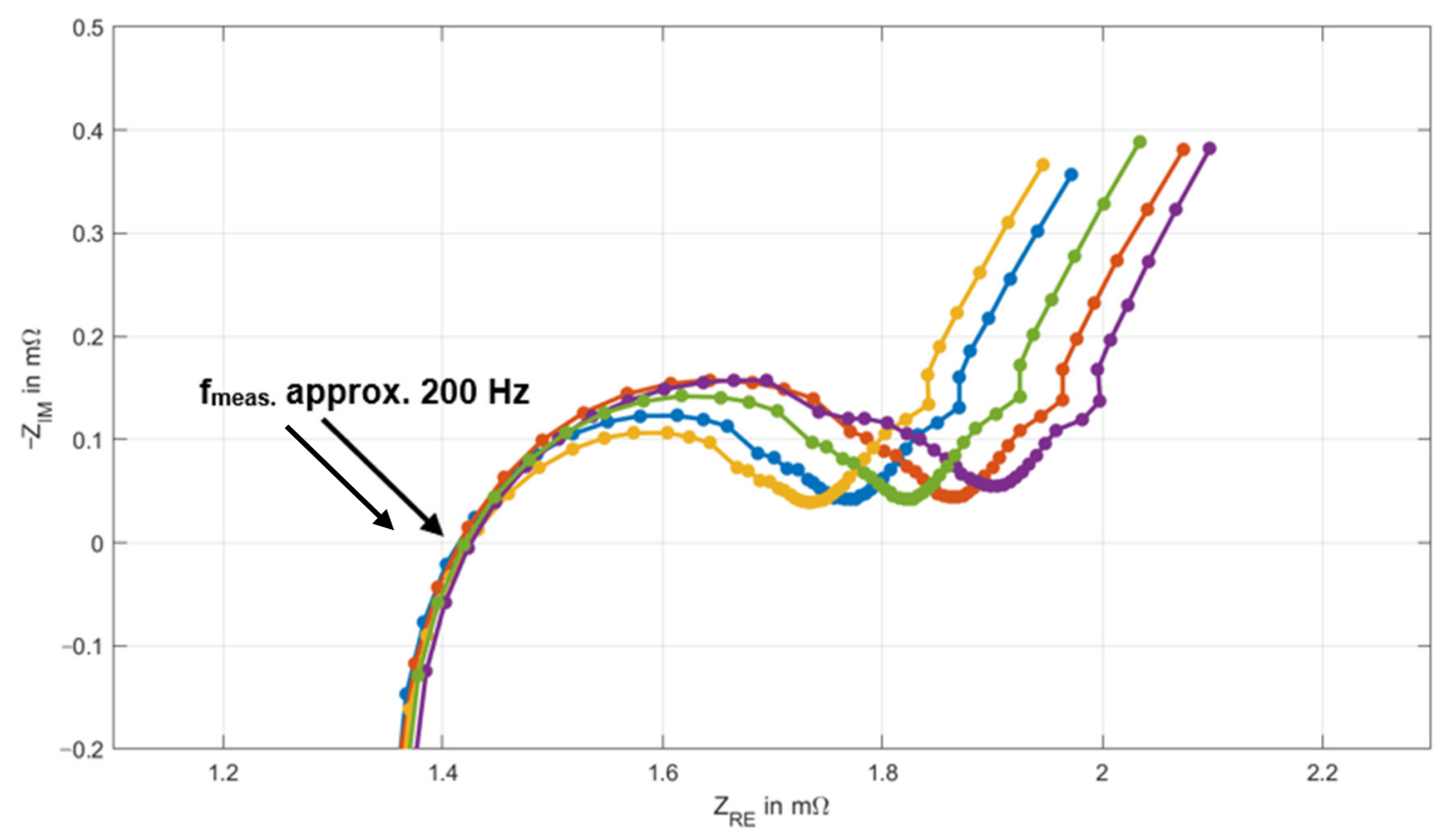

Figure 11. Impedance spectra at 30\% SOC of the modules. Modules 1 and 3 were shifted.

From the available spectra, it is clear that the modules have a measurable scattering. Modules 3 and 4 are particularly noticeable. Even an optical evaluation of the spectra shows a widening of the spectrum $\left(R_{02}\right)$ of Module 4 compared to the other modules. The two other evaluation characteristics, $I m_{1}$ and $I m_{2}$, are also the largest in this comparison. This suggests that the aging of Module 4 is greater (and therefore its performance is lower) than that of the other modules. Module 3 is the opposite of Module 4; it has the best measurements of this comparison, which indicates less aging and potentially longer use in the second life compared to Module 4 . An absolute statement about aging is not possible because all modules of the comparison could have aged strongly. For absolute statements 
about aging, the comparison with a new battery module is necessary as a reference. Table 5 shows the relative deviations of the modules compared to the best value. Formula (6) describes the equal weighting of the parameters $I m_{1}, I m_{2}$ and $R_{02}$.

$$
E I S_{S O H, \varnothing}=\frac{I m_{1}+I m_{2}+R_{02}}{3}
$$

Table 5. Evaluation of the module spectra with the characteristic points. Shading represents the order of the aged modules.

\begin{tabular}{ccccc}
\hline Module No. & $\boldsymbol{I m}_{\mathbf{1}}$ & $\mathbf{I m}_{\mathbf{2}}$ & $\boldsymbol{R}_{\mathbf{0 2}}$ & $\boldsymbol{E I S}_{\mathbf{S O H}, \boldsymbol{}}$ \\
\hline 1 & $115 \%$ & $107 \%$ & $121 \%$ & $114 \%$ \\
2 & $148 \%$ & $112 \%$ & $148 \%$ & $136 \%$ \\
3 & $100 \%(0.106 \mathrm{~m} \Omega)$ & $100 \%(0.039 \mathrm{~m} \Omega)$ & $100 \%(0.300 \mathrm{~m} \Omega)$ & $100 \%$ \\
4 & $148 \%$ & $139 \%$ & $158 \%$ & $148 \%$ \\
5 & $133 \%$ & $106 \%$ & $135 \%$ & $125 \%$ \\
\hline
\end{tabular}

The best module of this test method is Module 3, and the worst is Module 4. It is clear that modules perform consistently well or poorly on the selected evaluation criteria. More differentiated evaluations would be desirable but are not possible due to the instability and evaluability of other partial ranges of the impedance spectra. $I m_{1}$ and $R_{02}$ proved to be particularly suitable aging indicators. Here the differences in measurement results were most pronounced.

\subsection{Capacity Test}

During the capacity tests, the modules used here show measurement results that exceed the nominal capacity of new modules. This may be due to the additional integration over the CV step, but the discharge amount in this step is small. Due to the increased capacity, the authors assume that the modules are underestimated in the data sheet.

For the capacity evaluation, the module with the largest capacity was used as a reference and all other modules were normalized to this module (see Figure 12).

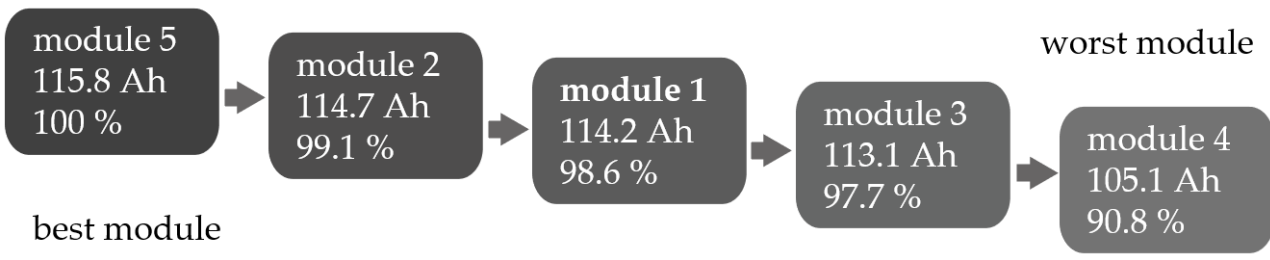

Figure 12. Evaluation of the capacity of the battery modules from Step 3 of the test procedure.

The percentage deviation from the best to the worst module is $9.2 \%$. A heavily aged module is thus well recognizable by the capacity test. More subtle differences (e.g., between Modules 1 and 2) are difficult to detect.

\subsection{Comparison of Methods}

The modules were characterized using EIS, the internal resistance tests and the capacity tests. From the measurement results, a relative aging condition evaluation of the modules could be generated. The results of the relative aging condition assessments vary depending on the measurement procedure. The results are summarized in Table 6.

A low internal resistance value is an indicator for a good module using the CI method; the same applies to the measured value $\mathrm{R}_{02}$ using the EIS method. In the capacity test, this is reversed. Here, a large charge quantity is an indicator of a good module. 
Table 6. Comparison of the measurement methods. Shading represents the order of the aged modules.

\begin{tabular}{|c|c|c|c|c|c|}
\hline $\begin{array}{c}\text { Measurement } \\
\text { Method }\end{array}$ & Best Module & & $\leftrightarrow$ & & Worst Module \\
\hline $\begin{array}{c}\mathrm{CI} / \text { internal } \\
\text { resistance }\end{array}$ & $\begin{array}{c}\text { Module } 3 \\
100 \%\end{array}$ & $\begin{array}{c}\text { Module } 1 \\
104 \%\end{array}$ & $\begin{array}{c}\text { Module } 2 \\
106 \%\end{array}$ & $\begin{array}{c}\text { Module } 5 \\
108 \%\end{array}$ & $\begin{array}{c}\text { Module } 4 \\
115 \%\end{array}$ \\
\hline EIS & $\begin{array}{c}\text { Module } 3 \\
100 \% \\
\end{array}$ & $\begin{array}{c}\text { Module } 1 \\
114 \%\end{array}$ & $\begin{array}{c}\text { Module } 5 \\
125 \%\end{array}$ & $\begin{array}{c}\text { Module } 2 \\
136 \%\end{array}$ & $\begin{array}{c}\text { Module } 4 \\
148 \%\end{array}$ \\
\hline Capacity test & $\begin{array}{c}\text { Module } 5 \\
100 \%\end{array}$ & $\begin{array}{c}\text { Module } 2 \\
99.1 \%\end{array}$ & $\begin{array}{c}\text { Module } 1 \\
98.6 \%\end{array}$ & $\begin{array}{c}\text { Module } 3 \\
97.7 \%\end{array}$ & $\begin{array}{c}\text { Module } 4 \\
90.8 \%\end{array}$ \\
\hline
\end{tabular}

In all tests, Module 4 was clearly identified as the most aged module. The differences compared to the other tested modules lead to the conclusion that Module 4 is least suitable for long-term second-life use. The assessment of the other modules with regard to their suitability must be more differentiated, as the different measuring methods produced inconsistent module evaluations. In this context, Module 3 is to be highlighted. While Module 3 often generated the best measurement results of a series of measurements during the EIS and internal resistance measurements, the remaining capacity of Modules 1,2 and 5 is higher. It should be noted that the deviation from the best module is only approximately $2.3 \%$, and the capacity rating is therefore given a low weighting in this comparison. Module 3 is therefore regarded as the module with the lowest aging of the five tested modules. In addition, it can be seen that EIS provides significantly more sensitive results than the other used methods.

Another inconsistency is the EIS rating of Modules 2 and 5 compared to the internal resistance rating. While EIS measurements of Module 2 showed similarly poor results as Module 4, the internal resistance measurements of Module 2 always appear better than those of Module 5, which was rated better by EIS. In addition, it is noticeable that Modules 2 and 5 are the best modules with regard to capacity rating. An explanation for these deviations is not known, but this observation underlines the thesis that capacity measurements do not allow a generally valid statement about the aging condition of a battery module [7].

The evaluation of the EIS measurements was so far performed with an equal weighting of the parameters $I m_{1}, I m_{2}$ and $R_{02}$. In future research, the electrochemical significance of the parameters $I m_{1}, I m_{2}$ and $R_{02}$ must be weighted so that the significance of the measurement can be increased.

If we look at the initial cost of the measuring devices, we can see that the CI method and the capacity test can be easily integrated by measuring current and voltage. Measuring devices with which EIS can be performed are significantly more expensive in comparison. Considering the necessary test duration, the acquisition costs and the sensitivity, the CI method is the most suitable method.

The CI method has shown that at lower charge states, the internal resistances increase. This is due to a steeper OCV curve so that the voltage jump is larger and was also described by Wildfeuer et al. [13] An increasing module resistance at high SOC could not be observed, which indicates good preservation of the low-contact resistances for the measurements with the CI method. Furthermore, a low internal resistance results in a higher power capability, as more current can flow until the lower discharge voltage is reached due to the voltage drop at the internal resistance.

The results show that the methods are suitable for the quantitative evaluation of the aging states of the modules. However, because only five modules were tested, significantly more modules must be tested to increase the statistical certainty. Further measurements with more modules are planned and also tests with as-new modules so that a statement in comparison with the new condition of the modules can be made. This allows a more quantitative $\mathrm{SOH}$ specification and increases the based dataset and statistical outliers can be identified. Additional cycling is important to check how the reversible aging processes may further change the results. Cyclization makes it possible to determine an aging process 
so that the condition of delivered modules can be identified more easily. Following this, a more accurate estimation of the remaining usage time should be possible.

It is shown that an individual measuring technology alone provides limited information, but the combination of methods increases the expressiveness. A capacity test cannot properly describe the true aging of the cells, battery modules with a similar aging history can be more difficult to distinguish. Subtle differences can be better detected by using EIS or CI methods. Both methods determine similar module ratings and hence a better gradation of the module aging is possible. Heavily aged modules can be reliably detected with any of the named methods.

It is conceivable that in the future, large single cells will be built and used. This will require improved test equipment for EIS, as the current state of the art (Gamry Inc.) will probably not be precise enough, as the internal resistance of the cells will be very low and the capacity very high. EIS measurement techniques of single cells are basically applicable at the system level, but appropriate measuring equipment for EIS at higher voltages is missing. The electrometer's voltage range is the limiting factor [27].

A further challenge is the low $\mu$-ohm range, as contacting errors of any kind will then have an increasing impact on CI and EIS measurement methods. As a consequence, the results will inevitably become less accurate.

\section{Conclusions}

In summary, the measurement techniques CI, EIS and the capacity test were experimentally compared to each other to classify their applicability under the aspects of test duration, sensitivity and investment costs of the measuring devices. The applicability of the measurement methods at the module level is given. The measurement technique places high demands on the test setup in order to measure the module properties and not the measurement setup.

The detailed sensitivity analysis shows that heavily aged modules can be detected with all the methods mentioned. Normal aged modules cannot be sufficiently distinguished by a capacity test, and the CI and EIS methods are more sensitive and allow more precise aging determination. In terms of time, $\mathrm{CI}$ and EIS analyses are significantly faster to perform than a capacity test.

Considerable differences can also be observed in the cost of the measuring equipment used to perform the measurement methods. Due to their higher sensitivity, the measuring instruments used to perform EIS measurements place high demands on the measuring setup and are therefore usually more expensive.

For integration into SESSs, the CI method is best suited, as current peaks can occur during operation due to the loads. If the current peak is $1 \mathrm{C}$ and reference data are available for the SOC, the aging can be determined. This allows in-service aging monitoring so that important reference data can be recorded for the particular battery type, providing predictability for modules of the same type that have not aged as much. Depending on the application, the selection of the most suitable measurement method must be determined on the basis of the investment costs, the desired sensitivity (which, in turn, imposes measurement setup requirements), the number of pieces to be tested and the available test time.

Author Contributions: D.K.: conceptualization, methodology, software, validation, formal analysis, investigation, resources, data curation, writing of the original draft. T.J.: conceptualization, methodology, validation, formal analysis, investigation, resources, writing — review and editing. F.L.: discussion, project administration. M.K.: discussion, supervision. All authors have read and agreed to the published version of the manuscript.

Funding: This research was funded by the German Ministry for Economic Affairs and Energy under grant number 0350021A-NetProsum2030.

Institutional Review Board Statement: Not applicable.

Informed Consent Statement: Not applicable. 
Data Availability Statement: The data are not publicly available due to the data required to reproduce these findings forms part of an ongoing study.

Acknowledgments: The authors would like to thank the Physikalisch-Technische Bundesanstalt (PTB), especially Department 3.6 for the provision of climate chambers and measuring instruments and the professional exchange. We acknowledge support by the German Research Foundation and the Open Access Publication Funds of Technische Universität Braunschweig.

Conflicts of Interest: The authors declare no conflict of interest.

\section{References}

1. European Commission. Communication from the Commission to the European Parliament, the Council, the European Economic and Social Committee and the Committee of the Regions: A New Circular Economy Action Plan. Brussels. March 2020. Available online: https:/ / eur-lex.europa.eu/legal-content/EN/ALL/?uri=COM:2020:98:FIN (accessed on 28 December 2020).

2. Casals, L.C.; García, B.A.; Canal, C. Second life batteries lifespan: Rest of useful life and environmental analysis. J. Environ. Manag. 2019, 232, 354-363. [CrossRef] [PubMed]

3. Kwade, A.; Haselrieder, W.; Leithoff, R.; Modlinger, A.; Dietrich, F.; Droeder, K. Current status and challenges for automotive battery production technologies. Nat. Energy 2018, 3, 290-300. [CrossRef]

4. Viswanathan, V.V.; Kintner-Meyer, M. Second Use of Transportation Batteries: Maximizing the Value of Batteries for Transportation and Grid Services. IEEE Trans. Veh. Technol. 2011, 60, 2963-2970. [CrossRef]

5. Rallo, H.; Casals, L.C.; De La Torre, D.; Reinhardt, R.; Marchante, C.; Amante, B. Lithium-ion battery 2nd life used as a stationary energy storage system: Ageing and economic analysis in two real cases. J. Clean. Prod. 2020, 272, 122584. [CrossRef]

6. Käbitz, S. Investigation of the Aging of Lithium-Ion Batteries Using Electroanalysis and Electrochemical Impedance Spectros-copy. Ph.D. Thesis, RWTH Aachen University, Aachen, Germany, 2016.

7. Martinez-Laserna, E.; Sarasketa-Zabala, E.; Sarria, I.V.; Stroe, D.-I.; Swierczynski, M.; Warnecke, A.; Timmermans, J.-M.; Goutam, S.; Omar, N.; Rodriguez, P. Technical Viability of Battery Second Life: A Study From the Ageing Perspective. IEEE Trans. Ind. Appl. 2018, 54, 2703-2713. [CrossRef]

8. Blömeke, S.; Mennenga, M.; Herrmann, C.; Kintscher, L.; Bikker, G.; Lawrenz, S.; Sharma, P.; Rausch, A.; Nippraschk, M.; Goldmann, D.; et al. Recycling 4.0. In Proceedings of the 7th International Conference on ICT for Sustainability, Bristol, UK, 21-27 June 2020; pp. 66-76.

9. Barré, A.; Deguilhem, B.; Grolleau, S.; Gérard, M.; Suard, F.; Riu, D. A review on lithium-ion battery ageing mechanisms and estimations for automotive applications. J. Power Sources 2013, 241, 680-689. [CrossRef]

10. Schuster, S.F.; Brand, M.J.; Campestrini, C.; Gleissenberger, M.; Jossen, A. Correlation between capacity and impedance of lithium-ion cells during calendar and cycle life. J. Power Sources 2016, 305, 191-199. [CrossRef]

11. Westerhoff, U. Klassifizierung Von Lithium-Ionen-Batteriezellen Mittels Kenngrößenbasierter Methoden; Dr. Hut: München, Germany, 2019.

12. Waag, W.; Käbitz, S.; Sauer, D.U. Experimental investigation of the lithium-ion battery impedance characteristic at various conditions and aging states and its influence on the application. Appl. Energy 2013, 102, 885-897. [CrossRef]

13. Wildfeuer, L.; Wassiliadis, N.; Reiter, C.; Baumann, M.; Lienkamp, M. Experimental Characterization of Li-Ion Battery Resistance at the Cell, Module and Pack Level. In Proceedings of the 2019 Fourteenth International Conference on Ecological Vehicles and Renewable Energies (EVER), Monte-Carlo, Monaco, 8-10 May 2019; pp. 1-12.

14. Eddahech, A.; Briat, O.; Vinassa, J.-M. Determination of lithium-ion battery state-of-health based on constant-voltage charge phase. J. Power Sources 2014, 258, 218-227. [CrossRef]

15. Weng, C.; Feng, X.; Sun, J.; Peng, H. State-of-health monitoring of lithium-ion battery modules and packs via incremental capacity peak tracking. Appl. Energy 2016, 180, 360-368. [CrossRef]

16. Campestrini, C.; Keil, P.; Schuster, S.F.; Jossen, A. Ageing of lithium-ion battery modules with dissipative balancing compared with single-cell ageing. J. Energy Storage 2016, 6, 142-152. [CrossRef]

17. Somandepalli, V.; Biteau, H. Cone Calorimetry as a Tool for Thermal Hazard Assessment of Li-Ion Cells. SAE Int. J. Altern. Powertrains 2014, 3, 222-233. [CrossRef]

18. Biteau, H.; Nava, N. Transportation of Li-ion Batteries: The State of Charge Parameter. p. 5. Available online: http://nts.uniduisburg-essen.de/aube/aube17/paper/Session\%2016/S16P2\%20Biteau\%20-\%20Nava.pdf (accessed on 30 December 2020).

19. Barai, A.; Uddin, K.; Chevalier, J.; Chouchelamane, G.H.; McGordon, A.; Low, J.; Jennings, P. Transportation Safety of Lithium Iron Phosphate Batteries-A Feasibility Study of Storing at Very Low States of Charge. Sci. Rep. 2017, 7, 5128. [CrossRef] [PubMed]

20. Schmidt, J.P. Verfahren zur Charakterisierung und Modellierung von Lithium-Ionen Zellen; KIT Scientific Publishing: Karlsruhe, Germany, January 2013.

21. Bauer, M. Elektrische und Mechanische Verfahren zur Detektion von Alterungseffekten in Lithium-Ionen-Batterien. Ph.D. Thesis, Technische Universität München, Munich, Germany, 2017.

22. Barsoukov, E.; Macdonald, J.R. Impedance Spectroscopy: Theory, Experiment, and Applications, 2nd ed.; Wiley-Interscience: Hoboken, NJ, USA, 2005. 
23. Zhu, J.; Sun, Z.C.; Wei, X.Z.; Dai, H.F. A new lithium-ion battery internal temperature on-line estimate method based on electrochemical impedance spectroscopy measurement. J. Power Sources 2015, 274, 990-1004. [CrossRef]

24. Petzl, M.; Kasper, M.; Danzer, M.A. Lithium plating in a commercial lithium-ion battery-A low-temperature aging study. J. Power Sources 2015, 275, 799-807. [CrossRef]

25. Stroe, D.I.; Swierczynski, M.J.; Stan, A.-I.; Knap, V.; Teodorescu, R.; Andreasen, S.J. Diagnosis of lithium-ion batteries stateof-health based on electrochemical impedance spectroscopy technique. In Proceedings of the 2014 IEEE Energy Conversion Congress and Exposition (ECCE), Pittsburgh, PA, USA, 14-18 September 2014; pp. 4576-4582.

26. Kucevic, D.; Tepe, B.; Englberger, S.; Parlikar, A.; Mühlbauer, M.; Bohlen, O.; Jossen, A.; Hesse, H. Standard battery energy storage system profiles: Analysis of various applications for stationary energy storage systems using a holistic simulation framework. $J$. Energy Storage 2020, 28, 101077. [CrossRef]

27. Gamry Instruments Inc. Reference 3000 Potentiostat/Galvanostat/ZRA Operator's Manual. Available online: https://www. gamry.com/assets/Uploads/Reference-3000-Operators-Manual.pdf (accessed on 3 December 2020). 